Esta obra está bajo una Licencia Creative Commons Atribución-NoComercial-Compartirlgual 4.0 Internacional

(c) (1) (8)(2)

Los varones de La Plata

Juan Bautista Branz y Homero Lanavecchia

DOI: https://doi.org/10.24215/16696581e226

Aceptado: 15-11-2019

\title{
Los varones de La Plata
}

\section{The men of La Plata}

\author{
Juan Bautista Branz juanbab@yahoo.com.ar \\ https://orcid.org/0000-0001-6991-663X
}

Instituto de Altos Estudios; Universidad Nacional de San Martín; Consejo Nacional de Investigaciones Científicas y Técnicas/ Universidad Nacional de La Plata (Argentina)

\section{Homero Lanzavecchia hlanzavecchia@gmail.com https://orcid.org/0000-0002-0879-471X}

Centro de Historia Argentina y Americana; Facultad de Humanidades y Ciencias de la Educación; Universidad Nacional de La Plata (Argentina) 


\section{Resumen}

En el siguiente artículo analizaremos una selección de fuentes y documentos históricos de diversas instituciones de la ciudad de La Plata complementando, también, con la exploración sobre la formación de la carrera del Servicio Militar en Argentina (SMO). Pondremos el foco de observación comparando qué tipo de masculinidades promocionaban tanto las instituciones del denominado Estado ampliado, como la propuesta por el Estado en sus diversas prácticas y discursos. Con esto, pensaremos cuál es el modelo de ciudadanía deseada a principios del siglo XX en Argentina pero, específicamente, entre las particularidades de la ciudad de La Plata, haciendo un doble juego semántico entre el nombre de la ciudad y la referencia a los varones de clases dominantes de los cuales nos encargaremos de estudiar en este trabajo.

Palabras Clave: masculinidad; ciudadanía; Estado; nación.

\section{Abstract}

In the following article we will analyze a selection of historical sources and documents from various institutions in the city of La Plata, also complementing the exploration of the formation of the Military Service career in Argentina (SMO). We will focus on comparing what kind of masculinities promoted both the institutions of the so-called expanded State, and the one proposed by the State in its various practices and speeches. With this, we will think about the desired citizenship model at the beginning of the 20th century in Argentina but, specifically, among the particularities of the city of La Plata, making a double semantic game between the name of the city and the reference to the men of dominant classes of which we will study in this work.

Keywords: masculinity; citizenship; State; nation.

Este trabajo se basa en la comparación de dos espacios. Uno estructurado desde el naciente Estado argentino, y el otro modelado por actores desde lo que denominaremos Estado ampliado. Entendemos por Estado ampliado al conjunto de instituciones que vehiculizan los intereses y valores de la clase dominante (Gramsci, 1973). Este tipo instituciones corresponderían, según Gramsci, a una segunda función del Estado (en su concepción e 
imagen más tradicional), las cuales colaborarían con el proyecto dominante en el campo de la cultura y la intelectualidad.

Así, haremos foco en la modelación y formación de un tipo de masculinidad imaginada y soñada por las clases dominantes (dirigentes del proyecto político fundador de Nación) correspondida con la extensión a diversas instituciones cercanas territorial, ideológica y moralmente a la matriz producida desde el nuevo Estado. Analizaremos cómo el Servicio Militar Obligatorio (pensado como herramienta del Estado para el adoctrinamiento del ciudadano) y el rugby como espacios de sociabilidad y socialización de clases dominantes abonaron a la construcción identitaria de un tipo de "ciudadano deseable"; vinculado, particularmente, a una idea europeizante de varón, cumpliendo y constituyendo ciertos parámetros estéticos, retórico y éticos para la conformación no sólo del nuevo Estado sino del aparato productivo.

El rugby, desde la década de 1910 en delante, se cristalizará como el círculo de contención y tránsito de personajes que obtuvieron u obtendrán prestigio social. El rugby será uno de los espacios donde se reproduzca esa cultura europea deseada por las bases de conformación de una nueva nación. Será el espacio deportivo de distinción en la ciudad de La Plata, ciudad inventada bajo la mirada iluminista y racional del proyecto civilizador. Será el lugar donde se perpetúe el sistema moral que distingue a los caballeros y a los honrados hombres, cuyo prestigio social atribuido en la ciudad, se confirmará en la participación de un juego cargado de rudeza y agresión física. Es que también es el espacio donde se reproducirá el modelo masculino dominante por excelencia, según los criterios de clasificación de lo que, para el Estado, será un verdadero hombre: templado, racional, culto, educado. Pero complementariamente viril, corajudo, audaz y valiente, con una hombría a sostener ante cualquier contingencia.

Pensar, analizar y narrar la masculinidad dominante, en clave sociohistórica, nos otorga algunas pistas para pensar en las tramas de poder, en la distribución desigual de capitales, ya sea en las esferas política, económica, cultural, étnica, genérica y, por supuesto, simbólica, de la sociedad argentina en los albores del siglo XX.

\section{Una capital para Buenos Aires}

La fundación de la ciudad de La Plata en noviembre de 1882 puede enmarcarse dentro de la conformación del naciente Estado-nación argentino y la búsqueda por expandir las instituciones de control del mismo. Pensada como una "segunda Bueno Aires", "la ciudad de las diagonales" fue creada desde cero a través del ingenio de Dardo Rocha y los anhelos de solidificación de las bases por parte el Estado argentino.

Question, Vol. 1, N. ${ }^{\circ}$ 64, octubre-diciembre 2019. ISSN 1669-6581

Instituto de Investigaciones en Comunicación | Facultad de Periodismo y Comunicación Social | Universidad Nacional de La Plata La Plata | Buenos Aires | Argentina

Página 3 de 19 
Una vez federalizada Buenos Aires en 1880, la búsqueda de una capital para la provincia se volvió clave y fue Dardo Rocha quien de forma sostenida envió proyectos a las Cámaras para cumplir dicho objetivo. Luego de varios viajes a lo largo de su vida -Europa, Estados Unidos y África- Rocha tenía en su cabeza varios modelos de ciudades que iban creciendo al ritmo del "progreso" y fueron dichos modelos los que iban a cristalizar en la construcción de la ciudad de La Plata. Dentro de varias opciones posibles de emplazamiento de la nueva capital, las Lomas de la Ensenada es la elegida debido a su puerto natural (Troisi Melean, 2006).

Pero detrás de la fundación de La Plata no sólo subyacían los anhelos de Rocha por ser alguna vez presidente, sino también la búsqueda del progreso y los cánones de civilización europeos. De esta forma 'La Plata es concebida como una Buenos Aires 'más perfecta', en el sentido que toda una generación de líderes latinoamericanos entiende como tal" (Troisi Melean, 2006: 74). Como se puede observar, la fundación de la ciudad de La Plata está en consonancia con los ideales de progreso que el flamante Estado-nación argentino promulga y no sólo se ve sino que se piensa como una nueva y mejor representante de dichos ideales que Buenos Aires.

El plan de homogeneizar una imagen ideal del "ser argentino", suscribía al proyecto de construir un ciudadano deseable, a partir de pensarlo dentro del marco civilizatorio, consecuente para concebir a la "razón" como modo legítimo y correcto para moverse en el mundo social. Dice Adamovsky,

(...) el ciudadano deseable era el que actuaba políticamente de manera 'razonable' (es decir, no con esas acciones directas o callejeras que solían emplear muchos trabajadores). Era también uno blanco y de origen europeo. Y como los blancos, por obra de las sucesivas oleadas de inmigración, tendieron a concentrarse en la región pampeana, implícitamente se identificaba al argentino 'típico' con el de esas zonas. En las partes del interior en las que había una población predominantemente mestiza se hicieron todos los esfuerzos para evitar que se 'notara'. De lo que estamos hablando aquí es de la formación de una peculiar identidad nacional que sostenía que el 'ser argentino' tenía que ver con determinada cultura (ser 'civilizado', 'europeo'), e implícitamente se asociaba a un determinado origen étnico (blanco) y a una región (la pampeana, particularmente la ciudad de Buenos Aires). Implícitamente, esta definición de 'lo argentino' creaba una jerarquía entre los argentinos y servía para disciplinar a las clases subalternas (2012: 65).

La exportación del modelo civilizatorio no sólo es impulsado por las elites dirigentes que, desde el Estado, procura la formación de una Argentina "civilizada" y de un "ser argentino", consecuente con el modelo europeo político, cultural, social y económico. También la 
paraestatalidad de instituciones como el rugby expone el deseo de los sectores mejor acomodados en la estructura capitalista.

El rugby en la ciudad de La Plata está conformado por sujetos que acumulan diferentes -y máscapitales que muchos otros sujetos de otros grupos de pertenencia u otro tipo de instituciones. Familias tradicionales, capital escolar acumulado, trayectoria social prestigiosa, capital social caudaloso y de privilegio, son la tendencia de los participantes del campo. El tipo de intervención en diferentes espacios sociales y las instituciones que se conectan en esas intervenciones, dan muestra de lugares de privilegio. Es por eso que optamos por pensar que el rugby, sus practicantes, modelan sectores de privilegio que, pensados desde la noción de distinción y legitimidad social y cultural, se configuran como dominantes en el mundo social.

\section{Ocio y espacio público}

Para el ocio, explica De Luca (2003), se arreglaron los paseos públicos como la Plaza de la Municipalidad (Moreno), la de la Policía (Rivadavia), los parques Saavedra y San Martín (actual parque Vucetich) y se construyó un portal que representaba el "arco de entrada" al Paseo del Bosque, en el casco de la estancia de los Iraola y que, junto al Pabellón de Música estilo art nouveau instalado en la Plaza de la Legislatura (hoy Plaza San Martín) constituyeron centros de esparcimiento con mayor atractivo.

El hipódromo se inauguró el 8 de setiembre de 1884. La organización de carreras estuvo a cargo del Club Hípico o Club de Carreras que antecedieron al Jockey Club. En sus instalaciones de 7 entre 48 y 49, en el hipódromo y en el balneario de Punta Lara se nucleó a lo más granado de la sociedad platense

En enero de 1885, un grupo de vecinos se reunió en el local de Aquiles D’Atri, en 49 entre 4 y 5 , con la intención de fundar un club dedicado a la práctica de dos deportes "de moda": la gimnasia y la esgrima. La convocatoria se publicó en el diario El Día (edición Nro. 259) y aunque no hay documentación fehaciente que la acredite, se considera que allí se iniciaron las actividades del Club de Gimnasia y Esgrima La Plata, con relación directa a la política de difusión del Club de Gimnasia y Esgrima de Buenos Aires que pretendía "inducir a caracterizados vecinos de las ciudades más importantes del país a fundar clubes deportivos de igual denominación, regidos uniformemente por el apotegma 'mens sana in corpore sano'”. Justamente el secretario de la institución porteña, José María Penne, se radicó (cumpliendo con la Ley de Residencia) como funcionario del Consejo de Higiene Pública y fue uno de los impulsores de aquella asamblea del 1885. 
Luego de dos meses, y debido a ciertas desavenencias entre dirigentes, se conformaron dos grupos que derivaron en la creación de dos entidades independientes. El Club Social de La Plata (1887) y el Club Belgrano (con perspectiva política) que antecedieron a la fundación del actual Club de Gimnasia y Esgrima La Plata. En 1905 nació el Club Atlético Estudiantes (actual Estudiantes de La Plata).

Los fracasos del sector empresario en las instituciones, favorecieron el desarrollo de las asociaciones sin fines de lucro -clubes de barrio- que fueron ganando espacio desde principios del siglo XX. En el campo deportivo, se enumeran las instituciones Gutenberg, Everton, Universal, Atenas, Asociación Coronel Brandsen, Deportivo La Plata, Unión Vecinal, Círculo Cultural Tolosano, Platense, Riachuelo, Sud América, La Plata Rugby Club, Los Tilos, Tacuarí, Villa Ribera, Juventud, Meridiano V, Asociación Mayo, Chacarita Platense, Deportivo Villa Elisa, Estrella de Berisso, Villa Albino, Náutico Ensenada. En el ámbito del desarrollo social y cultural, Asociación Sarmiento, Biblioteca Euforión, Asociación Alborada, Centro de Fomento Los Hornos, Club Atlético City Bell y las transnacionales Club de Leones y Rotary Club Internacional.

Se menciona al club El Círculo, institución cerrada y exclusiva de un determinado estrato social que estableció, y continúa estableciendo vínculos permanentes entre las familias de mayor arraigo, como

\begin{abstract}
se advierten en las reuniones sociales que habitualmente se realizan en sus instalaciones y que ha permitido la participación de los miembros de familias caracterizadas como Artola, Ballvé, Cieza Rodríguez, Condomí Alcorta, del carril, Jáuregui, Lanusse, Mercante, Molina Salas, Pachano, Rivarola, Sánchez Viamonte, Saraví Cisneros y VillaAbrille, entre otras" (De Luca, 2003: 89).
\end{abstract}

La lógica asociacionista atraviesa a las instituciones deportivas de la ciudad, conformando espacios destinados al ocio de diferentes grupos sociales. La deportivización de la vida cotidiana comienza a naturalizarse entre los habitantes de La Plata, y unos pocos clubes se erigen como parte de un círculo de sociabilidad ( $\mathrm{y}$ homosociabilidad) entre las clase dominantes, donde se reproducen las "buenas costumbres" y los modos refinados de pensar, sentir y vivir el mundo social (Branz, 2018). 


\section{La conformación del "buen ciudadano"}

Este proceso de centralización estatal se vio acompañado, y a su vez acompañó, la creación de nuevas élites estatales y profesionales (Plotkin y Zimmermann, 2012), portadoras de un conjunto de saberes profesionales (médicos, militares, educativos, etcétera). Dichos saberes conformaron un corpus común de concepciones que compartían todas las profesiones y que fueron utilizadas para dar forma a la idea del "buen ciudadano", el "buen hombre" y la "buena mujer", así como sus desviaciones. Es decir que a medida que el Estado iba tomando terreno también lo hacían estas concepciones.

Es en este contexto que la ley de Ricchieri de 1901 comienza a tomar cuerpo haciendo base en esas preconcepciones de lo que era ser "buen ciudadano": propietario, blanco y hombre. Estas cuestiones dejaron por fuera de la ciudadanía política a una serie de actores sociales que quedaron relegados a la marginalidad ciudadana hasta casi la mitad del siglo XX, como muestran en profundidad los estudios de Adriana Valobra (2011).

Esta idea de pasar del miliciano al soldado profesional (que aún no era ejército regular) comienza, hacia la última década del siglo XIX, a hilvanarse con la idea de la instrucción nacional. De ahí la razón del llamamiento a los ciudadanos y no a cualquier sujeto de la sociedad: la idea de inculcar ideales como el de orden, disciplina y deber y un sentido de misión que la patria impone caracterizó esa convocatoria (García Victorica, 1911).

Es por esto que el análisis del Servicio Militar Obligatorio no puede estar separado de la construcción del ciudadano y del futuro sufragante que se crea con la Ley Sáenz Peña, el cual incorpora características esencialmente masculinas como la participación en la vida económica y en la asistencia social (Ansaldi, 2000). Al mismo momento en que se estaban conformando las esferas de desarrollo que se asignarían modélicamente a los varones, sucedía lo mismo con los ámbitos que se definirían como plenamente femeninos. Al concebir a la mujer sólo como procreadora y cuidadora, sus ámbitos de desarrollo debían ser acordes a su rol en la sociedad, por lo que fueron relegadas a lo doméstico. Por otro lado, el varón, debido a su mandato social de proveedor familiar, estuvo más relacionado con el ámbito público y por ende, en el mercado de trabajo y en la política (Valobra, 2011). A estos roles, en una época de inestabilidad de las fronteras y, concomitantemente, definición de las mismas; no puede dejar de agregarse el rol del varón de defensor.

En las fuentes analizadas podemos ver una preocupación común en la poca materia prima de ciudadano que había en la sociedad argentina. Durante los debates de la Ley Ricchieri era una problema de central importancia el hecho de que los que debían defender a la patria (y por ende encarnar sus ideales) eran "de los peores elementos y por los medios injustos e 
inconvenientes" (García Victorica: 148). Esta preocupación se ve también en el Informe Dutil (1) al expresar que hay "gran escasez de gente capacitada".

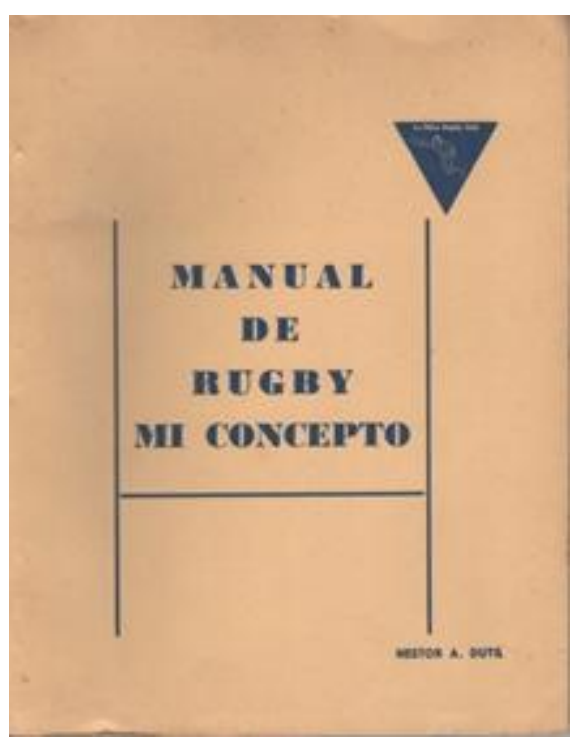

Figura 1. Tapa de Manual de Rugby. Mi Concepto, de Néstor Dutil.

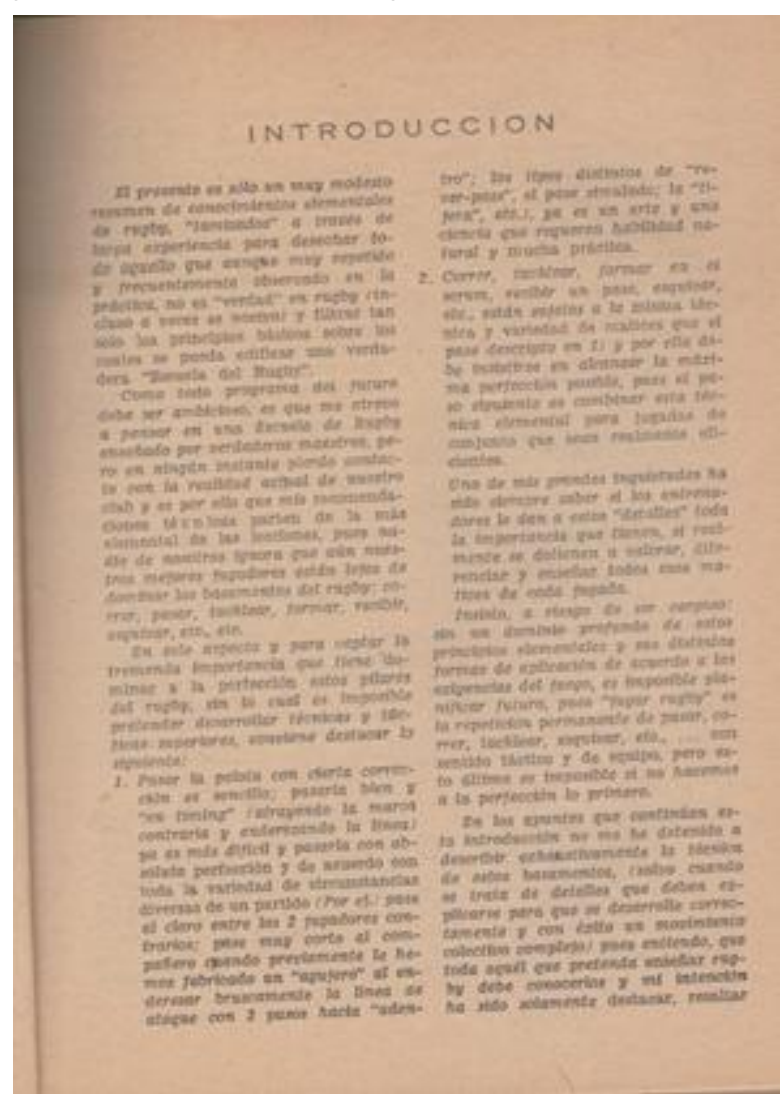

Figura 2. Introducción. Manual de Rugby. Mi Concepto, de Néstor Dutil. 


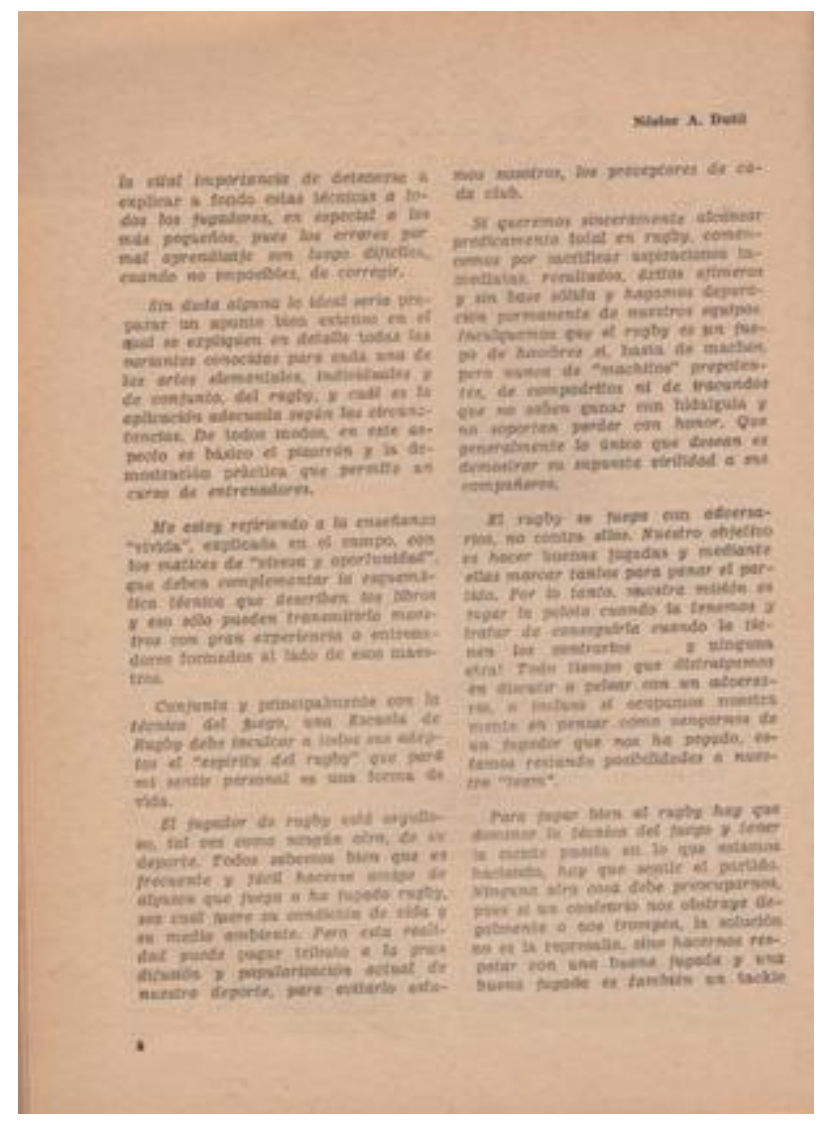

Figura 3. Hoja 8. Manual de Rugby. Mi Concepto, de Néstor Dutil. 


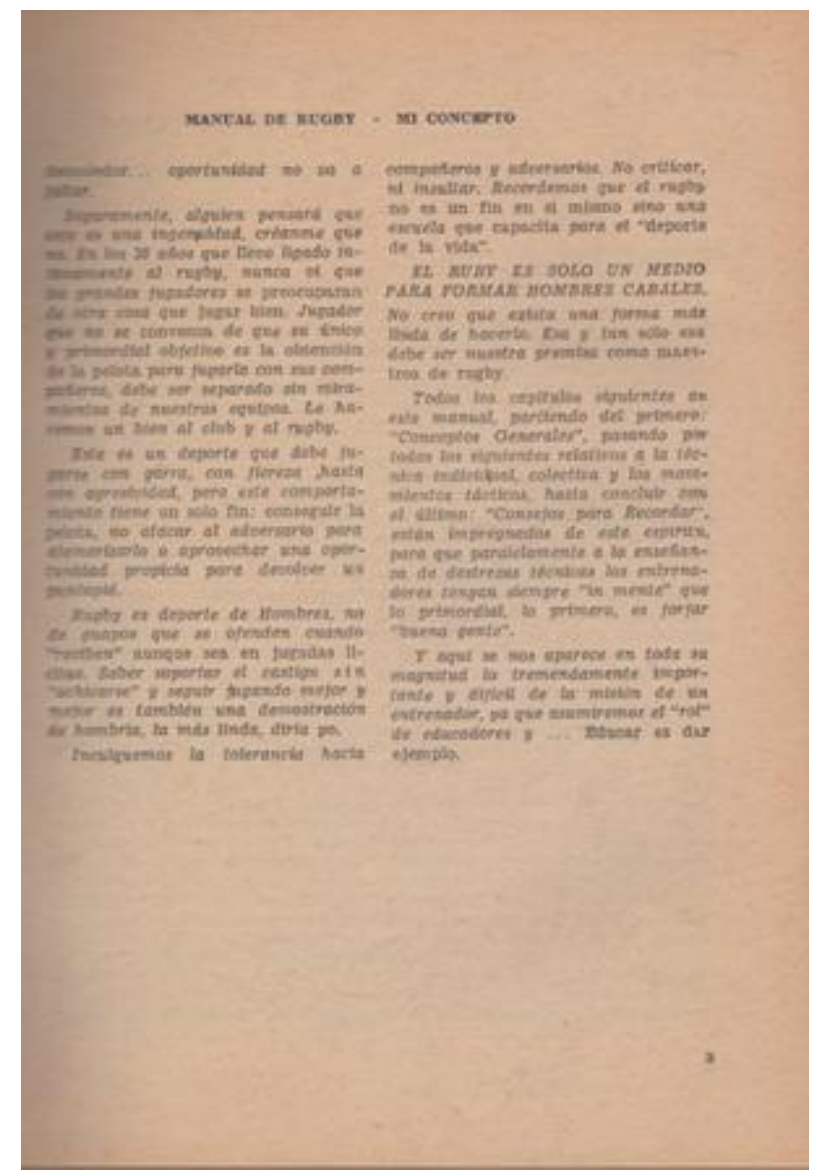

Figura 4. Hoja 9. Manual de Rugby. Mi Concepto, de Néstor Dutil.

Es decir que tanto los defensores de la patria como los de "los valores del deporte" debían reunir una serie de formas de actuar y relacionarse con los otros que los harían dignos de formar parte tanto del país como del equipo titular.

Otra cuestión que se relaciona es la preocupación por la virilidad. No sólo la Ley Ricchieri excluía a los cobardes al hablar de la deserción como un acto de falta de valor sino que excluía también a las mujeres de hecho, es decir que tácitamente no eran portadoras de dicha característica. Esta cuestión puede ser analizada en una doble clave. Por un lado, la preocupación sobre la desorganización del ejército y la falta de lealtad hacia el mismo, muchas veces propia de que los soldados estaban allí contra su voluntad. Por otro lado, podemos pensar que esas deserciones eran producto de unas masculinidades que escapaban a la norma; la idea de valentía, fuerza tanto física como mental, abnegación, propias todas ellas de una masculinidad hegemónica no se esperaba que todos los varones reflejaran. Así, la 
deserción puede ser vista como un escape no solo en búsqueda de libertad sino en oposición y confrontación a esa masculinidad militar impuesta (Kimmel, 1997).

Además, hacía del esfuerzo físico y la violencia una forma de "hacer machos" a los que no lo eran mediante "los plantones de semanas y meses, los planazos, las estaqueaduras, el cepo, y otros suplicios chinos, hasta el fusilamiento sobre el tambor" (García Victorica, 1911). Este intento por moldear una masculinidad hegemónica centrada en la fuerza y la abnegación puede observarse en las constantes quejas sobre malos tratos a los soldados (mala comida, entrenamientos y tratos casi inhumanos, castigos atroces). Estas cuestiones son, en parte, desarrolladas por Johnatan Ablard (2017) al momento de analizar los debates entre militaristas, es decir, a favor del servicio obligatorio, y los antimilitaristas, aquellos quienes se oponían. Las alusiones que los primeros hacían a los segundos con respecto a su masculinidad evidencian los trasfondos que contenía ese debate: al llamarlos cobardes, afeminados e infantiles daban la pauta de que promovían la construcción de una masculinidad hegemónica afirmada en un cierto tipo de virilidad y poder.

Aunque no de forma directa el rugby genera algo similar cuando los propios jugadores hablan de que es "un deporte viril, fuerte y que siempre 'va de frente".

Como nos muestran las fuentes analizadas, el honor y el castigo eran de suma importancia a la hora de moldear a los varones (tanto platenses como argentinos). Tanto el Informe Dutil como la Reglamentación del Servicio Militar Obligatorio hacen especial hincapié en educar en la disciplina por medio de ciertas penalidades.

Los títulos XII y XIII que reglamentan la Junta de excepciones y las penalidades, respectivamente, denotan un gran interés por castigar a quienes no cumplen el SMO imponiéndoles -al detectarlos- más años de servicio. Es pertinente entender esta preocupación punitiva como una forma de disciplinamiento ante las deserciones, una de las formas más comunes de resistencias hacia esas masculinidades hegemónicas que el SMO imponía. Es decir, esas penalidades estaban destinadas a castigar a los varones que escapaban a la norma (legal y masculinizante).

Pero el aspecto que más comparten el SMO y el rugby es su aspiración de ser los vehículos de la transformación hacia el "ciudadano tipo". Por un lado el Informe Dutil expresa en varias ocasiones que "el deporte es la quintaescencia del ser civilizado" haciendo gala de ser el rugby el portador de ciertos valores íntimamente ligados con el correcto desempeño como ciudadanos. Por el otro el SMO mediante la exclusión de mujeres, extranjeros e indígenas busca "limpiar" de malos valores al futuro ciudadano argentino.

El hecho de que el rugby crea tener cualidades transformadoras a nivel ciudadano puede ser la muestra de que el modelo de ciudadano masculino que intentó reproducir la Ley Ricchieri no 
llegó a todos los confines del territorio argentino y que en estos lugares fue el Estado ampliado el que tomo la posta.

Con lo anteriormente visto se ve necesario ahondar un poco más en los alcances que la Ley Ricchieri tuvo y su relación con el Estado ampliado.

\section{Capital de varones}

Además de los análisis en clave de masculinidades, la clase atraviesa tanto el SMO como el rugby platense. En el primero de los casos las cuestiones de clase generaron una doble problemática; por un lado los que encarnaban los verdaderos valores de la patria (masculina) eran los varones de clase alta pero los que normalmente hacían el servicio militar eran los pobres gracias a figuras legales como las del personero (2) o el trueque de servicio (3) que permitían a los ricos evadir el servicio. El hecho de que esto sucediera nos lleva a preguntarnos ¿qué validaba más la masculinidad? ¿El dinero o el valor? ¿La propiedad o la patria?

La figura del personero (figura que permitía que una persona tomara el lugar de otra en la realización del servicio militar y que, en general, se traducía en los hechos como la posibilidad de que un pobre hiciera el servicio en lugar de los ricos a cambio de dinero), fue eliminada en la letra pero no en su esencia. La idea de trocar el servicio a cambio de dinero ahora estaba avalada en el título III art. 17 de la ley en la cual "queda autorizada la permuta de servicio entre un conscripto a quien haya tocado el servicio de dos años, con un conscripto perfectamente apto de la misma clase a quien haya tocado el servicio de seis meses". Esta permuta estaba seguida de condiciones económicas como pagar una suma no menor a $\$ 600$ al padre del soldado que iba a trocar, pagar el papel con timbre que equivalía a $\$ 200$ y abonar $\$ 100$ a un mes de firmarse el contrato de permuta y $\$ 10$ todos los meses hasta que culminara el servicio. Estas condiciones estaban muy alejadas del ciudadano promedio por lo que, al igual que sucedía con la figura del personero, sólo una cierta clase social y económica podía acceder a estas figuras. Vale decir, se establecían condiciones de masculinidad para la realización del servicio y sobre ese perfil genérico se facilitaban las excepcionalidades o el suavizamiento de las condiciones de realización del servicio en función de la situación de clase.

Al mismo tiempo, las excepciones al servicio militar descriptas en el título XI de la ley son ejemplificadoras de la concepción de hombre y mujer que la reglamentación reproducía. En el art. 100, inciso b, se marcaba que se exceptuaría del servicio "al hijo de madre viuda o al hijo natural que atienda a la subsistencia de ésta o de un padre septuagenario o impedido". Así, esta ley reproduce la imagen de varón proveedor que sólo se aplica con la madre que ha perdido su "proveedor original". Al igual que en el inciso d.5 la única razón por la cual el 
"hombre de la casa" no pudiera salir a trabajar es si estaba impedido y no si era pobre; de esta forma la imagen construida es que la mujer no puede salir a trabajar aunque no estuviese impedida, se la cataloga como pobre y debe ser mantenida por su hijo o nieto. Como consecuencia de la propia construcción de la figura femenina, aunque hubiera una mujer en edad y capacidad para trabajar fuera de la casa, se exceptuaba al hijo/nieto varón para que ésta no tuviera que hacerlo y fuera él quien trabajase.

En el caso del rugby vemos cómo la fundación de varios clubes sociales platenses tiene una conformación "cerrada y exclusiva de un determinado estrato social que estableció, y continúa estableciendo vínculos permanentes entre las familias de mayor arraigo, como se advierten en las reuniones sociales que habitualmente se realizan en sus instalaciones (Branz, 2018).

En este caso la validación masculina del rugbier está dada por ambas claves: juega a un deporte varonil, viril y fuerte; y por otro lado posee dinero, que le permite tener su tiempo de ocio para practicar el mismo deporte que lo valida masculinamente.

\section{Virtudes corporales}

George Mosse (2000) realiza una genealogía del concepto de caballerosidad analizando cómo la noción de caballería -propia de la Inglaterra del siglo XIX- es tomada por las clases medias, para construir sus moralidades y sus costumbres. Mosse sostiene que la caballerosidad está asociada no sólo a los atributos físicos de un caballero (y su correspondiente virilidad, fuerza y coraje expresados en las posturas y en las apariencias corporales), sino a los modos correctos de comportarse.

El rugby sería un lugar más para entender una de las formas del "poder del imaginario masculino en una sociedad concreta" Archetti (2008: 43). Entonces, la pregunta es: ¿cuál es ese estilo masculino vinculado a la práctica deportiva en el rugby? El proceso socio/histórico del rugby indicaría que los agentes participantes del tienen mayores posibilidades para administrar culturalmente las diferencias en cuanto a la producción y reproducción de un estilo masculino, asociado a la construcción de una hexis corporal (4) y a su correspondiente representación mediante estrategias discursivas. El rugby, diría Dunning (2003), puede describirse como una batalla simulada entre equipos, pero también conforma un ámbito propicio para el despliegue de agresividad y potencia masculina. Para Bourdieu (1993), la exaltación de la virilidad está asociada al rugby. Pero ¿desde dónde la podemos pensar? ¿En dónde se traducen los valores, las estéticas, y las éticas que se institucionalizaron en el rugby? Una de las alternativas, son los cuerpos y sus usos legítimos que organizan y disponen el espacio, como estrictamente masculino.

Question, Vol. 1, N. ${ }^{\circ}$ 64, octubre-diciembre 2019. ISSN 1669-6581

Instituto de Investigaciones en Comunicación | Facultad de Periodismo y Comunicación Social | Universidad Nacional de La Plata La Plata | Buenos Aires | Argentina

Página 13 de 19 
El cuerpo es un continuo productor de sentido, una oportunidad para enfocar el análisis sobre los cuerpos del rugby. Porque el cuerpo se traduce como marca de lo posible. En este caso, de lo dominante (5), de lo legítimo. El cuerpo, según Le Breton (1999), no es una materia pasiva. Colabora en el proceso de producción simbólica en una época y en sociedades determinadas. Se configura como soporte de una teoría cultural que interviene e interpela al espacio social. Cada movimiento del cuerpo tiene la marca asignada según los condicionamientos de grupo interiorizados. Son propiedad de una comunicación social, de luchas, que expresan emociones y producen actos. Diría González, siguiendo a Harry Pross que "toda comunicación comienza en el cuerpo y a él regresa" (1999: 25). Para Citro (2006), sobre la materialidad común de los cuerpos se construyen prácticas socioculturales disímiles (técnicas corporales cotidianas, modos perceptivos, formas de habitar los espacios, gestos, expresión de emociones), otorgando la posibilidad de elaborar representaciones sobre esas corporalidades y de vincularse de maneras diferentes con el mundo.

Los atributos sobre la fuerza y el vigor colaboran para presentar y sostener la idea de un cuerpo naturalmente concebido en el rugby. Expresión de virilidad, marca de hombría, diferenciación radical de otros cuerpos. Se afirma en la contratapa del Boletín de julio de 1953, de La Plata Rugby Club:

\begin{abstract}
La naturaleza podrá habernos hecho fuertes, pero debemos ayudarla y conservar esa salud. Únicamente [sic] se consigue por el ejercicio metódico, o sea el entrenamiento [...] Por eso insistimos siempre tanto en que no deben faltar a las prácticas. En ellas se acostumbra el jugador a desarrollar sus condiciones naturales de vigor y fuerza y ensaya lo que más tarde deberá hacer en los partidos (6).
\end{abstract}

La idea de fuerza y vigor natural requiere de cierto discurso legitimador que se corresponda más con una esencia o un legado mágico, que con una construcción social y cultural del cuerpo. Social porque es parte de la concepción grupal sobre el cuerpo que un grupo determinado de nuestras sociedades comparte. Y cultural, porque materializa en el cuerpo una simbología, imágenes y representaciones que trazarán un puente directo con una estética y una ética dominante. Diría Bourdieu:

las prácticas deportivas que intentan dar forma al cuerpo son realizaciones, entre otras, de una estética y una ética en estado práctico. Una norma postural como andar/mantenerse derecho tiene, al igual que una mirada directa o un pelo corto, la función de simbolizar todo un conjunto de 'virtudes' morales -rectitud, sinceridad, honestidad, dignidad (confrontación 
cara a cara como una demanda de respeto)- y también virtudes físicas -vigor, fuerza, salud

(1993: 75).

Fuerza, vigor, potencia, revestidas de una moralidad vinculada a la templanza, la racionalidad, son necesariamente puestos en acto por los hombres que juegan al rugby. Responden a lo esperado en el campo de acción.

Con respecto al SMO una de las causas de excepción estaba relacionada con la enfermedad y los defectos físicos; dentro de esos defectos estaba la estatura. La reglamentación impone una talla mínima para ingresar en las unidades del ejército de 1 metro y 55 centímetros, por lo tanto todo aquel que no cumpliera con este requisito tenía un "defecto" o "enfermedad" y debía cumplir servicios auxiliares. Aquí se puede ver de qué forma el cuerpo está cargado de significación y funciona como "depositario de principios de visión y de división sexuantes" (Bourdieu, 1993: 11); la estatura, en este caso, estaba relacionada con la fuerza y la virilidad, características del propias del varón. Aquel que midiera menos de 1,55 mts. era considerado menos masculino y por ende carente de las cualidades de serlo; en este aspecto el foco estaba puesto en lo que el hombre no podía representar más que en lo que la mujer sí podía, puesto que si había una mujer que cumpliera los requisitos de estatura de toda formas no podía ingresar al ejército.

Si lo pensamos en relación al estereotipo de varón hegemónico, inalcanzable según Connell (1997), tanto el valor como el dinero son parte constitutiva de dicha masculinidad pero en el caso del SMO vemos que esta relación no está tan clara. Podríamos pensarlo en forma de relaciones de poder ya que el hecho de ser poseedor de la libertad de decidir sería la que validaría la masculinidad (el rico puede elegir validar su masculinidad a través del valor o del dinero, el pobre sólo a través del valor).

\section{Reflexiones finales}

A lo largo del presente trabajo hemos intentado tender un diálogo entre dos formas en la construcción del varón hegemónico argentino durante el siglo XX. Este proceso no sólo fue impulsado y vehiculizado por las instituciones estatales sino que, allí a donde éste no podía o no supo llegar, se desarrollaron una serie de actividades que continuaban con la afirmación de un modelo de varón.

Los clubes de rugby platenses funcionaron como ramificaciones del proyecto masculinizador, imprimiéndole sus propias características fruto de los atravesamientos de clase propios del deporte. El rugby se convirtió en uno de los espacios para mantener y contribuir a la ilusión de 
estar cerca de Europa. Desde allí se perpetraron y se conservan tradiciones, costumbres y valores emparentados con la cultura inglesa y francesa como posibilidad distintiva de "lo local". Es un giro hacia la distinguibilidad, directo y asociado a un privilegio autopercibido por los sujetos participantes del rugby. Es el espacio donde se enseñan las buenas y legítimas costumbres que, estratégica y eficazmente, construyen distinción moral, pero también estética, a la vez que se edifica una narrativa en donde la retórica del honor y la caballerosidad, diría Gayol, proveen un lenguaje propio. Donde además de nombrar ese mundo como legítimo, se pone a prueba poniendo el cuerpo y exhibiéndolo, ya que el honor en el rugby, se asocia a la reputación social. Es la forma que se aprende a ver y a ser visto, de ejercitar los criterios de clasificación moral, además de evaluar y ser evaluado. La masculinidad se evalúa constantemente. Es un espacio estrictamente jerárquico donde la posición de prestigio, emparentada con la forma de mostrar la hombría son constantemente puestas a prueba. Como condición heteronormativa, ligada a la clase (que también se pone a prueba) y a los modos dominantes de reproducir una verdadera hombría. El rugby mantiene la obsesión por instaurar jerarquías: económicas, culturales, etarias, étnicas y de género. Allí radica la eficacia de su carácter exclusivo y de privilegio. Someterse a esa jerarquización y lograr sostener el escalafón conseguido, es la prueba a pasar. Ese lugar se mantiene con esfuerzo, con dedicación, y con la performatividad tanto práctica como retórica. Palabras, gestos, actitudes normativas dentro del campo de una masculinidad hegemónica, deben asimilarse y reproducirse en el espacio que hemos estudiado, más allá que intentamos mostrar que las identidades y las valías que las recubren, son situacionales. Y que los hombres que juegan al rugby pueden, a la vez, estar atravesados por un tipo de masculinidad subalterna para los criterios de evaluación del campo (Branz, 2018).

La modelación de los cuerpos en el rugby, no sólo se corresponde con las reglas y con la lógica del deporte: una lógica en donde prevalece el contacto y el impacto entre los cuerpos de los sujetos que compiten. No: el uso de los cuerpos de hombres que juegan al rugby mantiene vínculo -más o menos directo- con la relación entre las clases y el género. Entre la posición en la que se ubican sus practicantes (heterogénea, claro; pero menos heterogénea que en otras porciones del espacio social) y su correlación con los modos de reproducir formas de ser hombre: posturas, gestos, usos de suplementos dietarios. La rigidez corporal es una característica distintiva de los jugadores de rugby. Dureza que se exhibe en varias modalidades: músculos tonificados y de gran volumen, o kilos acumulados que se encriptan en una estética dominante, dentro del campo del rugby.

A su vez, el cuerpo fue un objetivo de normalización tanto por el Estado mediante el SMO y las clases de educación física escolar, como por los clubes de rugby. Como contenedor de sentido, 
el cuerpo masculino hegemónico tomó forma de la mano con un imaginario de valores que lo acompañaban (virilidad, valentía, fuerza) y reforzaban su posición de poder frente a los demás géneros como también frente a los propios varones que no "habían dado el piné".

La motorización de un modelo cultural de varón, impulsado desde el Estado e instituciones que amplían el espectro y la influencia de este, será central desde la invención de la Nación. Se materializará en los cuerpos y en las narrativas regionales pero, fundamentalmente, en una narrativa nacional. La masculinidad dominante se convierte en práctica y discurso a través de instituciones que vuelven carne un modelo de sentir, percibir, actuar y vivir el mundo. Un mundo imaginado, representado y simbolizado desde los desniveles entre clases, géneros, etnias; desde la disputa por una cosmovisión pensada desde/en Europa y esencializada (y normalizada) por un Estado blanco, urbano, occidental y heteronormativo. La pregunta por la sociogénesis de la masculinidad, entendemos, es transversal a cada proceso político, económico y sociocultural que continúe luego de la fundación del Estado argentino.

Notas

(1) Dutil fue un reconocido jugador de La Plata Rugby Club. Promotor del rugby en La Plata, ex alumno del colegio Nacional, se destacó ocupando cargos en la UAR como presidente de la Comisión de Disciplina. Escribió el Manual de Rugby: Mi Concepto, impreso en 1974, con una tirada de 1200 ejemplares, y cuyo dinero por sus ventas donó al club.

(2) Figura legal que permitía exceptuarse del servicio a cambio de dinero.

(3) Figura legal que permitía trocar años de servicio con otros de la misma categorìa (también a través de dinero)

(4) Asociada por Bourdieu, entre otros, al cuerpo externo.

(5) Pensemos en las corporalidades construidas entre las hinchadas de fútbol argentino, en la constitución de las prácticas violentas, donde la puesta en acción de los cuerpos (en los combates) se transforma en una acción positiva, mientras que, desde la mayoría de los discursos sociales se estigmatiza y condena la práctica, como "animal" o "salvaje". Los discursos mediáticos hegemónicos son un claro ejemplo de la construcción de estos relatos. Para ampliar sobre la temática ver Alabarces, Pablo y otros (2005).

(6) Boletín Informativo Número 3 de LPRC, Año 1, Contratapa, Julio 1953 (aparece el nombre de la ciudad de La Plata, en ese momento "Eva Perón"). 


\section{Bibliografía}

Ablard, J. (2017). The barracks receives spoiled children and returns men: Debating Military Service, Masculinity and Nation-Building in Argentina, 1901-1930. The Americas, 74, pp. 299-329. doi: https://doi.org/10.1017/tam.2017.43

Adamovsky, E. (2012). Historia de la clase media argentina (sexta edición). Buenos Aires: Grupo editorial Planeta.

Ansaldi, W. (1999). Crear el sufragante: la universalización masculina de la ciudadanía política en argentina. La reforma electoral de 1912. Anales, Nueva Época, 2, Suecia.

Bourdieu, P. (1993). Deporte y clase social. En Materiales de sociología del deporte. Barcelona: Ediciones de La Piqueta.

Branz, J. B. (2018). Machos de verdad. Masculinidad, Deporte y Clase en Argentina. Una etnografía sobre hombres de sectores dominantes que juegan al rugby. La Plata, Buenos Aires: Editorial Malisia.

Citro, S. (2006). Variaciones sobre el cuerpo. Nietzsche, Merleau-Ponty y los cuerpos de la etnografía. En Matoso, E. (comp.). In-certidumbres del Cuerpo. Corporeidad, arte y sociedad. Buenos Aires: Letra Viva-Facultad de Filosofía y Letras, UBA.

Connell, R. (1997). La organización social de la masculinidad. En Ediciones de las Mujeres, Isis Internacional, Santiago, XXIII, pp. 31-48. Recuperado de https://bit.ly/2End7pM

De Luca, R. (2003). Familias platenses. Buenos Aires: Edigraf.

Dunning, E. (2003). El fenómeno deportivo. Estudios sociológicos en torno al deporte, la violencia y la civilización. Barcelona: Paidotribo.

García Victorica, J. A. (1911). El servicio militar obligatorio bajo sus diversos aspectos. Buenos Aires: La semana médica.

Gayol, S. (2008). Honor y duelo en la Argentina moderna. Buenos Aires: Siglo XXI Editores.

González, J. (1999). Convergencias paralelas: desafíos, desamores, desatinos entre antropología y comunicación. En Estudios sobre las Culturas Contemporáneas, época 11, V(10), Colima, pp. 9-17.

Gramsci, A. (1973). Cartas de la cárcel. Buenos Aires: Nueva Visión.

Kimmel, M. (1997). Homofobia, temor, vergüenza y silencio en la identidad masculina. En Valdés, T. y Olavarría, J. (Comps.). Masculinidad/es. Poder y crisis (pp. 49-62). Ediciones de las Mujeres, 24, Isis Internacional, Santiago, Chile.

Le Breton, D. (1999). Las pasiones ordinarias. Antropología de las emociones. Buenos Aires: Ediciones Nueva Visión.

Mosse, G. (2000). La imagen del hombre. Madrid: TALASA Ediciones. 
Plotkin, M. y Zimmermann, E. (2012) (Comps). Las prácticas del Estado. Política, sociedad y elites estatales en la Argentina del siglo XX. Buenos Aires: Edhasa.

Troisi, J. (2006). Dardo Rocha, el último porteño. La Plata; Instituto Cultural de la Provincia de Buenos Aires.

Valobra, A. (2011). Claves de la ciudadanía política femenina en la primera mitad del siglo XX en Argentina. Revista Estudios, 24, 7-44. Memoria Académica. Recuperado de http://www.memoria.fahce.unlp.edu.ar/art_revistas/pr.7377/pr.7377.pdf 